\title{
FINE-SCALE GENETIC STRUCTURE AND SOCIAL ORGANIZATION IN FEMALE WHITE-TAILED DEER
}

CHRISTOPHER E. COMER, ${ }^{1}$ D. B. Warnell School of Forest Resources, University of Georgia, Athens, GA 30602, USA JOHN C. KILGO, USDA Forest Service, Southern Research Station, P.O. Box 700, New Ellenton, SC 29809, USA GINO J. D'ANGELO, D. B. Warnell School of Forest Resources, University of Georgia, Athens, GA 30602, USA TRAVIS C. GLENN, Savannah River Ecology Laboratory, Drawer E, Aiken, SC 29802, USA, and Department of Biological Sciences, University of South Carolina, Columbia, SC 29208, USA

KARL V. MILLER, ${ }^{2}$ D. B. Warnell School of Forest Resources, University of Georgia, Athens, GA 30602, USA

\begin{abstract}
Social behavior of white-tailed deer (Odocoileus virginianus) can have important management implications. The formation of matrilineal social groups among female deer has been documented and management strategies have been proposed based on this well-developed social structure. Using radiocollared $(n=17)$ and hunter or vehicle-killed $(n=21)$ does, we examined spatial and genetic structure in white-tailed deer on a 7,000-ha portion of the Savannah River Site in the upper Coastal Plain of South Carolina, USA. We used 14 microsatellite DNA loci to calculate pairwise relatedness among individual deer and to assign doe pairs to putative relationship categories. Linear distance and genetic relatedness were weakly correlated $(r=-0.08, P=0.058)$. Relationship categories differed in mean spatial distance, but only $60 \%$ of first-degree-related doe pairs (full sibling or mother-offspring pairs) and $38 \%$ of second-degree-related doe pairs (half sibling, grandmother-granddaughter pairs) were members of the same social group based on spatial association. Heavy hunting pressure in this population has created a young age structure among does, where the average age is $<2.5$ years, and $<4 \%$ of does are $>4.5$ years old. This-combined with potentially elevated dispersal among young does-could limit the formation of persistent, cohesive social groups. Our results question the universal applicability of recently proposed models of spatial and genetic structuring in white-tailed deer, particularly in areas with differing harvest histories.
\end{abstract}

JOURNAL OF WILDLIFE MANAGEMENT 69(1):332-344; 2005

Key words: genetics, home range, microsatellites, Odocoileus virginianus, radiotelemetry, relatedness, rose-petal hypothesis, Savannah River Site, South Carolina, white-tailed deer.

The white-tailed deer is an economically and ecologically important wildlife species throughout the eastern and midwestern United States. Widespread recovery of deer populations in the eastern United States in the last 50 years has brought about necessary changes in deer management strategies (McShea et al. 1997). The current economic and ecological implications of white-tailed deer and overabundant deer populations are wellestablished (Conover 1997), and understanding white-tailed deer social organization is important in designing effective management strategies.

Social behavior of white-tailed deer has been extensively studied. Previous studies have shown that female deer form cohesive social groups that use similar habitat ranges for much of the year (Hawkins and Klimstra 1970, Aycrigg and Porter 1997). Dispersal among female deer is typically low (<5\%, Kammermeyer and Marchinton 1976, Dusek et al. 1989), although Nelson and Mech (1992) observed 13-20\% dispersal in female white-tailed deer in Minnesota, and Nixon et al.

\footnotetext{
${ }^{1}$ Present address: Arthur Temple College of Forestry and Agriculture, Stephen F. Austin State University, Nacogdoches, TX 75962-6109, USA.

2 E-mail: kmiller@smokey.forestry.uga.edu
}

(1991) observed $40 \%$ dispersal in female fawns and $20 \%$ dispersal among yearling does in Illinois. In a 30-year series of studies of deer in the Adirondack Mountains in New York, several researchers developed a model for deer population expansion termed the "rose-petal hypothesis" (Porter et al. 1991). This hypothesis proposes that female deer populations expand as a series of overlapping home ranges that are similar to the petals of a rose. According to the model, female offspring are highly philopatric, establish home ranges that overlap that of their mother and have low dispersal rates (Porter et al. 1991). Based on radiotelemetry data, Tierson et al. (1985) identified several social groups of does in the Adirondack Mountains study area that consistently occupied overlapping winter and summer ranges and had low female dispersal (4\%). These social groups of associated does formed the basic units of the rose-petal model.

The rose-petal model implies that genetic structure exists in deer populations at the level of relationships among individual deer. Each succeeding generation of females forms approximately concentric rings of home ranges radiating outward. In support of this concept, Mathews and Porter (1993) found that members of a social group were 
DE- AI09-00SR22188

J. Wildl. Manage. 69(1):2005
Journal Article 2005

05-41-P

WHITE-TAILED DEER GENETIC STRUCTURE • Comer et al. 333 genetically similar according to allozyme analysis and spatially close according to radiotelemetry and visual association data. Therefore, the rosepetal hypothesis predicts a negative correlation between genetic relatedness and spatial distance among female white-tailed deer. Where different social groups have adjacent or overlapping ranges, genetically dissimilar individuals may occur in close spatial proximity. The occurrence of numerous genetically similar doe pairs that are spatially distant suggests that closely related deer do not have overlapping home ranges and are not behaving according to the predictions of the rose petal model. Specifically, does that are either mother-daughter or full siblings (first-degree relationship) would have overlapping home ranges (Porter et al. 1991). Furthermore, half-siblings or grandparent-grandchild pairs (second degree) likely would be members of the same social group and therefore would be spatially close. These predictions contrast with those of the "gas diffusion" model of deer behavior, in which deer diffuse or disperse from more populated areas to less populated areas until equilibrium is reached (Porter et al. 1991). In this case, little genetic structure would be apparent in the population and relationships between spatial and genetic distance would be weak or absent.

In application, the rose-petal hypothesis suggests that intensive removal of deer from a small area can create an area of low population density that will persist for more than 10 years (Porter et al. 1991). The effort required to manage deer in this limited area is likely less than that needed to reduce population density over a larger area. McNulty et al. (1997) tested this localized management strategy by removing a social group of 14 does from the Adirondack Mountains study area and observing the movements of radiocollared deer $(n=9)$ in adjacent social groups. After the removal, a local reduction in deer density was observed; however, deer in adjacent social groups did not respond by altering their home ranges. More recent analysis of the same removal test indicated that lower deer density persisted for 5 years post-removal (Oyer and Porter 2004). Although deer were present in the removal area, they apparently were descended from either females remaining in the removal area or immigrants from adjacent social groups (Oyer and Porter 2004). Based on these limited tests of its assumptions and effectiveness in a single geographic area, the localized management concept has been widely proposed for managing locally abundant white-tailed deer, especially in urban or suburban settings with deer-human conflicts (e.g., Kilpatrick and Spohr 2000, Grund et al. 2002, Porter et al. 2004).

The localized management concept has the potential to be an important tool for deer managers in areas where the underlying population model operates. However, testing of the model to date has been limited to the Adirondack Mountains study area. Several characteristics of the Adirondack deer herd are different from those found in other regions of the country, particularly in the southeastern United States. Like many northern deer herds, white-tailed deer in the Adirondacks migrate seasonally between summer and winter ranges (Tierson et al. 1985). The Adirondack study area has not been hunted since 1932, which has resulted in a very old age structure in the herd (Aycrigg and Porter 1997). Despite the lack of hunting pressure, deer densities in the Adirondacks are generally low due to low recruitment and periodic widespread mortality from severe winter weather (Aycrigg and Porter 1997). The influence of these herd characteristics on deer social behavior is not clear, but it could be substantial (Marchinton and Atkeson 1985). Southeastern deer herds are nonmigratory and typically have high recruitment and heavy hunting mortality, which results in a young age structure. To date, studies of deer population structure in the southeast have been at regional scales that do not address the social group structure of the rose-petal hypothesis (e.g., Leberg and Ellsworth 1999, Purdue et al. 2000). For these reasons, an investigation of fine-scale genetic and social structure in a southeastern deer herd is both timely and relevant.

We examined population structure in whitetailed deer in the Coastal Plain of South Carolina to determine whether social organization was consistent with the predictions of the rose-petal hypothesis and to evaluate the potential effectiveness of localized management. We determined the degree of home-range overlap and linear distance between point locations for female white-tailed deer. We used microsatellite DNA loci to measure pairwise genetic relatedness among deer. By determining the correlation between genetic and spatial distance measures, we were able to examine socio-spatial structure in the deer herd. Furthermore, we used specific categories of relatedness (e.g., full siblings) to examine their spatial relationship. Together, these analyses allowed us to determine whether social 


\section{DE- AI09-00SR22188 Journal Article}

334

WHITE-TAILED DEER GENETIC STRUCTURE

- Comer et al.
2005

05-41-P

J. Wildl. Manage. 69(1):2005 organization was consistent with the predictions of the rose-petal hypothesis.

\section{STUDY AREA}

The Savannah River Site (SRS) is an approximately 800-km² National Environmental Research Park encompassing portions of Aiken, Barnwell, and Allendale counties in South Carolina, USA. The SRS is administered by the U.S. Department of Energy (DOE) and managed jointly by DOE and Westinghouse, Inc. While active facilities occupy portions of the site, most of the SRS is undeveloped. The SRS is approximately $68 \%$ pine forest and consists primarily of variable-aged stands of longleaf (Pinus palustris) and loblolly ( $P$. taeda) pine (Imm and McLeod in press). Swamps and riparian bottomlands dominated by hardwoods, including oaks (Quercus spp.), sweetgum (Liquidambar styraciflua), and blackgum (Nyssa sylvatica), occupy $22 \%$ of the site. Upland hardwoods, including oaks and hickories (Carya spp.), represent approximately $7 \%$ of land cover. Forested stands are interspersed with open habitats such as powerline rights-of-way, recent timber harvests, and $\mathrm{road} /$ facilities areas. The SRS is within the upper Coastal Plain physiographic province.

The deer herd at SRS has been managed since 1965 by annual dog-drive deer hunts over much of the site. Management sets annual removal goals to maintain a sitewide population of 4,000 animals $\left(5 / \mathrm{km}^{2}\right)$ to minimize deer-vehicle collisions while maintaining a healthy population. Current population density varies across the site but generally is estimated at $4-6 \mathrm{deer} / \mathrm{km}^{2}$ in most areas (Novak et al. 1999). Despite the low deer density, deer-vehicle collisions on site roads are considered a management problem. From 1990-2000, the SRS averaged approximately 75 deer-vehicle collisions annually, and data indicate that sitewide reductions in deer density have not resulted in equivalent reductions in collision rates (Novak et al. 1999).

Our study area consisted of approximately 7,000 ha in the upland northwestern portion of the SRS, centered along a major site roadway. Vegetative cover and deer density in the study area were typical for upland portions of the SRS. The area was approximately bisected by Upper Three Runs Creek, which is a major site drainage. Managed hunts were not conducted in the study area during the 2000 and 2001 hunt seasons.

Extensive population and genetic studies of white-tailed deer have been conducted at the SRS using allozyme techniques and hunter-harvested animals. They found that populations in the Savannah River swamp and upland portions of the site differed demographically and genetically (Dapson et al. 1979, Ramsey et al. 1979) and found significant nonrandom clustering and genetic structure in deer harvested across the site (Scribner et al. 1997). These studies provide evidence for genetic structure in the SRS deer herd at larger landscape scales; however, they did not consider structure at the individual level.

\section{METHODS}

\section{Deer Capture}

Between January 2001 and August 2002, we captured female white-tailed deer using rocket and drop nets and by darting from vehicles or tree stands. Nets were placed on 0.1-0.2-ha food plots and baited with whole kernel corn and salt. We immobilized deer captured in nets with xylazine hydrochloride administered intramuscularly at 1 $\mathrm{mg} / \mathrm{kg}$ body weight. We darted deer from vehicles using spotlights and either Cap-Chur (Palmer Cap-Chur Equipment, Inc., Powder Springs, Georgia, USA) or Dan-Inject (Dan-Inject ApS, Borkop, Denmark) dart rifles. Darts were loaded with $3 \mathrm{cc}$ of xylazine hydrochloride $(1.8 \mathrm{ml}$ at 100 $\mathrm{mg} / \mathrm{ml}$ ) and Telazol (500 $\mathrm{mg}$ in solution). Due to the dense vegetation and large potential escape area, we used Pneu-Dart (Pneu-Dart, Inc., Williamsport, Pennsylvania, USA) transmitter darts to aid in deer recovery. In an effort to sample multiple deer from the same potential social groups, we focused capture efforts in certain locations. However, the dense year-round cover and low deer density limited our ability to identify and target members of apparent social groups.

We aged deer by tooth wear and replacement (Severinghaus 1949). For genetic analysis, we collected approximately $2 \mathrm{~cm}^{2}$ of ear tissue from the lower edge of 1 ear with a razor blade. Deer were individually marked with numbered brass ear clips and plastic ear tags and fitted with a 3-year radiocollar with an 8-hour mortality signal (Advanced Telemetry Systems, Isanti, Minnesota, USA). We administered a topical antibiotic on all external wounds and administered the systemic antibiotic tetracycline at $20 \mathrm{mg} / \mathrm{kg}$-body weight by subcutaneous injection. After processing, deer were given an intravenous injection of yohimbine hydrochloride at $0.06 \mathrm{mg} / \mathrm{kg}$ body weight to facilitate recovery from the immobilizing drugs. We monitored all deer until recovery before release. All capture and handling work was done in accor- 
DE- AI09-00SR22188

J. Wildl. Manage. 69(1):2005
Journal Article 2005

05-41-P

WHITE-TAILED DEER GENETIC STRUCTURE • Comer et al. 335 dance with University of Georgia Institutional Animal Care and Use Committee permit number A2002-10119-0.

\section{Radiotelemetry}

We collected year-round radiotelemetry data by triangulation using the loudest-signal method (Mech 1983). We used hand-held receivers and 3element Yagi antennae to take azimuths from permanently located and geo-referenced triangulation stations. We triangulated deer locations using sequential bearings, taking $<20 \mathrm{~min}$ to collect the 3-7 azimuths used to estimate the location of an individual deer (Nams and Boutin 1991). We divided days into 4 equal segments of $6 \mathrm{hr}$ each and collected locations approximately equally among the 4 segments. All locations were separated by at least $8 \mathrm{hr}$ to minimize the potential for autocorrelation among locations (Otis and White 1999). The mean angular telemetry error was $8.3^{\circ}(\mathrm{SE}=0.80)$ as determined by estimating bearings $(n=50)$ to 10 test transmitters placed at random, geo-referenced locations in the study area. Average transmitter to receiver distance during this study was $470.4 \mathrm{~m}$ ( $\mathrm{SE}=$ $420.2 \mathrm{~m})$.

We used the program LOCATE II to convert telemetry azimuths to UTM coordinates (Nams 1990). We plotted locations in ArcView (Environmental Systems Research Institute, Redlands, California, USA). For all deer with greater than 30 radiolocations, we estimated home range using the $95 \%$ kernel method in the animal movements extension for ArcView. We identified individuals with overlapping home ranges by visual inspection of ArcView polygons. For each pair with overlap, we calculated home-range overlap as a percentage of the average total home range for the 2 individuals:

$$
O=\frac{A_{11}}{\left[\left(A_{1}+A_{2}\right) / 2\right]} * 100
$$

where $O$ is the percent overlap, $A_{\mathrm{o}}$ is the area of overlap (in $\mathrm{m}^{2}$ ), and $A_{1}$ and $A_{2}$ are the homerange areas (in $\mathrm{m}^{2}$ ) of deer 1 and deer 2 , respectively. This value is equivalent to Cole's index of association (Cole 1949).

In addition to the radiocollared deer, we collected an approximately $20-\mathrm{cm}^{3}$ piece of abdominal muscle for genetic analysis from all deer killed during a management hunt in the 7,000-ha study area in September 2002. Hunters were interviewed immediately after the hunt to determine precise kill locations for each deer sampled. Additionally, we obtained muscle tissue samples from all deer killed by vehicle collisions in the study area during the period from April 2001 through December 2002. The locations of all deer-vehicle collisions were recorded using Global Positioning System (GPS).

\section{Genetic Analyses}

We froze and stored all tissue samples at $-70^{\circ} \mathrm{C}$. We extracted DNA from tissue samples using Qiagen DNEasy DNA isolation kits (Qiagen, Inc., Valencia, California, USA). Following extraction, we quantified DNA concentration in the resulting solution by $1 \%$ agarose gel electrophoresis with ethidium bromide staining and used lambda DNA for reference (Sambrook et al. 1989).

Anderson et al. (2002) identified 21 polymorphic microsatellite loci in white-tailed deer from Oklahoma. These loci were evaluated in 13 southern populations of deer and determined to be suitable for use in parentage and other population genetic studies (DeYoung et al. 2003). Based on analyses of 80 randomly chosen individuals from SRS, 14 of these loci were determined to be polymorphic and did not deviate significantly from the expectations of Hardy-Weinberg equilibrium (HWE; C. E. Comer, University of Georgia, unpublished data). Following DNA isolation, we used polymerase chain reaction (PCR) to amplify these 14 microsatellite loci using primers and reaction conditions described by Anderson et al. (2002). After amplification, PCR products were loaded onto 12-cm acrylamide microsatellite gels and electrophoresed in an ABI 377 analyzer (Applied Biosystems, Foster City, California, USA). To aid in distinguishing loci, primers were fluorescently labeled with 1 of 3 dyes (NED-2 amidite [NED], 6-carboxyfluorescein [6-FAM], or 6-carboxyhexafluorescein [HEX]) as identified in Anderson et al. (2002). An internal size standard (R-500, Genetix, New Milton, United Kingdom) also was loaded with each sample to allow size identification of microsatellite alleles. Chromatograms derived from microsatellite runs were initially analyzed with GENESCAN (Applied Biosystems), and then imported into GENOTYPER (Applied Biosystems) for characterization of alleles. We evaluated the loci for HWE and linkage disequilibrium (LD) using the web version (3.4) of GENEPOP (Raymond and Rousset 1995). Due to the large number of comparisons, we applied sequential Bonferroni correction to 


\section{DE-AI09-00SR22188 Journal Article}

336

WHITE-TAILED DEER GENETIC STRUCTURE

- Comer et al. these tests (Rice 1989). We used the program CERVUS to calculate heterozygosity and polymorphic information content (PIC) for all loci (Marshall et al. 1998).

\section{Data Analyses}

We examined the relationship between genetic relatedness and spatial distance to examine the extent to which SRS deer behaved in a manner consistent with the rose-petal hypothesis. This hypothesis describes a complex set of behaviors leading to the formation of population structure; therefore, it is difficult to devise a single statistical test to determine its presence or absence. Other authors have noted the difficulty in biological interpretation of population genetics data (Bohonak 1999, Balloux and Lugon-Moulin 2002). Rather than relying on a single test, we used a weight-of-evidence approach to consider evidence in favor of the rose-petal hypothesis. The approach consisted of a series of correlation tests using different subsets of the available data, which was followed by the examination of the spatial characteristics of specific relationship categories.

To assess genetic structure of the population, we performed statistical correlation analyses between genetic distance measures and spatial distance measures. Because it predicts that closely related does form overlapping home ranges, the rose-petal hypothesis predicts a negative correlation between genetic relatedness and spatial separation. That is, we expect more closely related deer pairs to have smaller distances between them. We assessed genetic separation using pairwise relatedness among individual does. We estimated relatedness using the unbiased $r_{x y}$ statistic of Queller and Goodnight (1989). The $r_{x y}$ statistic varies from -1 to 1 , with zero indicating the relatedness in a random draw of alleles from the population. A positive value indicates the genotypes of a pair of individuals are more closely related than a random draw from the population. Pairwise relatedness scores were calculated using the program SPAGeDi 1.0 (Hardy and Vekemans 2002). Allele frequencies and background relatedness scores were derived from a larger $(n=$ 368) sample of deer from the entire SRS. Using the relatedness scores, we assessed the degree of correlation between relatedness and spatial measures for 3 sets of deer pairs: the set of all does sampled, a subset consisting of only adult deer, and a subset of deer with overlapping home ranges.

For the entire set of deer pairs, we used the linear distance between point locations as the inde- pendent spatial variable. Point locations were either kill locations or geometric means of telemetry locations. The SRS management hunts used dogs to drive deer to stationary hunters. However, D'Angelo et al. (2003) showed that deer rarely leave their home range during these hunts. Therefore, kill locations are assumed to occur within normal home ranges for these deer. To assess potential bias from using kill locations versus mean telemetry locations, we conducted a bootstrap simulation analysis using the radiocollared does. For each of 10,000 iterations, the simulation randomly chose (with replacement) a known telemetry location for each deer as a simulated kill location. For each iteration, these simulated kill locations were used to calculate pairwise distances between individuals. We then calculated correlations between the simulated distances and pairwise relatedness. By comparing the correlations with simulated distances to the correlation for these same deer using mean telemetry locations, we were able to assess potential bias due to the use of kill locations in the analysis.

We assessed correlation between linear distance and relatedness using the Mantel test of matrix correspondence (Smouse et al. 1986). The Mantel test compares the correlation between the observed matrices to correlations observed between a large number $(n=10,000)$ of random permutations of the matrix columns and rows. The test accounts for the fact that the set of all pairwise distances (genetic or spatial) is not independent (Smouse et al. 1986). Mantel tests are a common method for assessment of correlation between genetic and spatial distance matrices (Diniz-Filho and Campos-Telles 2002), and they have been used to compare $r_{x y}$ values and linear distances (e.g., Ohnishi et al. 2000). In addition to the Mantel tests, we assessed genetic structure using the spatial autocorrelation procedure of Peakall et al. (2003). We used the program GenAlEx 5.1 to perform spatial autocorrelation calculations (Smouse and Peakall 1999). For spatial autocorrelation, we set the analysis to consider 12 distance classes of $1 \mathrm{~km}$ each and used permutations $(n=999)$ to derive probabilities associated with the autocorrelation.

Because white-tailed deer fawns typically stay in close association with their mothers for at least 1 year after birth (Hawkins and Klimstra 1970) and dispersal is highest in the fawn and yearling age class, spatial location of fawns may not accurately represent adult range (Nixon et al. 1991, Nelson and Mech 1992). Inclusion of fawns potentially 
DE- AI09-00SR22188

J. Wildl. Manage. 69(1):2005
Journal Article $\quad 2005$

05-41-P

WHITE-TAILED DEER GENETIC STRUCTURE • Comer et al. 337 biased our results toward greater correlation between spatial and genetic distance. Therefore, we conducted separate Mantel test and spatial autocorrelation analyses using only adult does that were $>1.5$ years old at the time of sampling.

For radiocollared does, we assessed the correlation between home-range overlap and relatedness. The Mantel test was not applicable in this analysis due to the high number of empty matrix elements (i.e., many doe pairs had zero home-range overlap). However, the lack of independence among pairwise values is likely to be less important in this instance because each individual is involved in only a small number of pairwise interactions. Therefore, we calculated Spearman's rank correlation coefficient $r_{s}$ to assess correlation between home-range overlap and relatedness (Ratnayeke et al. 2002). Note that for calculations involving home-range overlap, the sign of the correlation coefficient is opposite of that for linear distance (as overlap increases, linear distance decreases).

In a complementary test to the correlation analyses, we examined the spatial relationships of doe pairs related at specified levels. Estimates of relatedness like the $r_{x y}$ score can be used to classify pairs of individuals into relationship categories; however, a likelihood-based approach provides a more powerful method for making these assignments (Blouin 2003). The program Kinship 1.2 allows tests of various hypotheses regarding the relationships between pairs of individuals (Queller and Goodnight 1989). The program calculates a ratio between the likelihood of a given hypothesis (e.g., full siblings) versus a null hypothesis (e.g., unrelated). Based on simulation of many hypothetical pairs $(n=10,000)$, the program determines the likelihood ratio needed to reject the null hypothesis for a given pair at a user-defined alpha level.

We used Kinship 1.2 to assign all doe pairs to 1 of 3 relationship categories: first degree (including mother-offspring and full sibling pairs), second degree (grandmother-granddaughter, halfsibling, aunt-niece pairs), and unrelated. We then used graphical methods to examine the extent to which these relatedness categories corresponded to differences in spatial distance between pairs. Closer examination of the spatial relationships of doe pairs in each category allowed us to specifically address predictions of the rose-petal hypothesis such as the prediction that closely related deer (e.g., category 1 or 2 related) should share significant portions of their range.

\section{RESULTS}

\section{Radiotelemetry}

We captured and radiocollared 17 female deer at the SRS in winter/spring 2001 and 2002, including 9 captured in rocket nets and 8 through darting. These included 4 doe fawns $(\leq 1$ year old), 4 yearlings (1.0-2.0), 8 adults (2.0-4.5), and 1 older adult $(>4.5)$. Of 17 does, 12 survived through the study period. Two were killed in managed hunts, 1 was killed by a vehicle, and 2 died of unknown causes. One doe made an approximately 8-km dispersal movement in February 2002, when she was approximately 20 months old. A second doe also apparently dispersed. After occupying 1 range for 8 months, she moved approximately $4.5 \mathrm{~km}$ in October 2001 when she was 17 months old and stayed in the new range for 2 months. However, she died of unknown causes before sufficient radiolocations were obtained to delineate a new home range. For the correlation analyses, only the natal ranges (predispersal) of these deer were used for spatial calculations. The use of natal ranges for these does provides an upper limit estimate of correlation between genetic and spatial distance compared to adult (post-dispersal) ranges. The remaining 15 does were consistent in their range use and did not show seasonal or dispersal movements.

Home ranges for the 17 does were calculated based on an average of 81 radiolocations (range 43-142). Deer were monitored over an average period of 315 days (range 51-846). Deer were included only if they had $>10$ radiolocations in at least 2 seasons (winter, spring, summer, fall). Two deer had radiolocations in only 2 seasons, but the remaining 15 were monitored in all 4 seasons. The mean 95\% kernel home-range size was 197 ha (range 89-365 ha). Of 136 potential radiocollared deer pairs, 17 pairs had home ranges that had an average overlap of $21.1 \%$ (range $0.6-77.2 \%$ ).

We obtained muscle tissue samples from 15 does killed during management hunts within the 7,000-ha study area, from 4 does killed in vehicle collisions, from 1 predated deer, and from 1 capture mortality. With the 17 radiocollared does, the total number of tissue samples was 38 (Fig. 1). Overall, we sampled 8 doe fawns, 11 yearlings, 16 adults, and 2 older adults. Based on a deer density of 5 deer $/ \mathrm{km}^{2}$ and a sex ratio near 1:1 (Novak et al. 1999), our sample represents approximately $20-25 \%$ of does within the 7,000-ha study area. This percentage is comparable to the $30-35 \%$ of does radiocollared in the Adirondacks study lead- 
DE- AI09-00SR22188 Journal Article

338

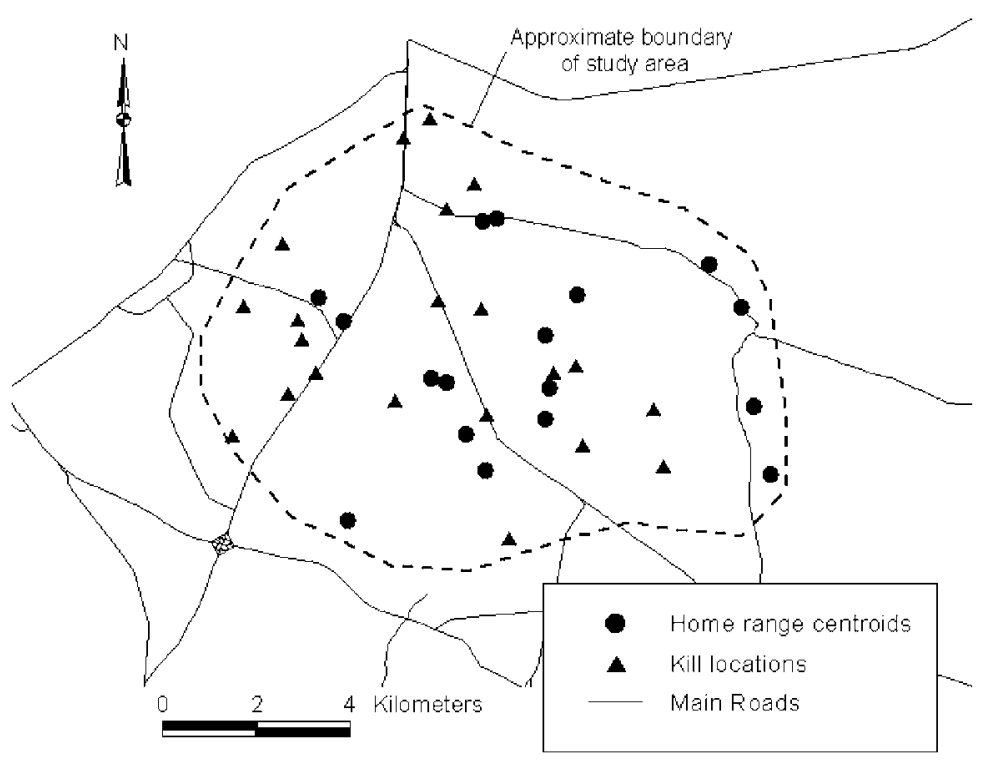

Fig. 1. Home-range centroids (for radiocollared deer) and kill locations for 38 female whitetailed deer used in population structure analyses at the Savannah River Site, Aiken, South Carolina, USA, 2001-2002. The dashed line shows the approximate boundary of the study area for this study.

ing to the formation of the rose-petal hypothesis (Mathews and Porter 1993). Among the 703 doe pairs, average linear distance between point locations (kill locations or mean of telemetry locations) was 4,690 m (SE 88.2; range 301-11,714).

\section{Microsatellites}

Genetic diversity for the 368 deer analyzed is reported in Table 1 . The mean number of alleles per locus was 11.1 and ranged from 3 to 22 . The mean observed heterozygosity for all loci was 0.696 (range 0.375-0.867) and the mean polymorphic information content was 0.681 (range 0.352-0.895). Similar to the results of DeYoung et al. (2003), we did not find evidence for linkage disequilibrium in our samples.

Three microsatellite DNA loci (BM4208, ETH152, N) deviated from Hardy-Weinberg equilibrium in the entire population of 368 individuals from SRS (Table 1). All 3 showed a deficiency of heterozygotes compared to expectations. This may be due to the inclusion of related deer in the larger sample or it may indicate the presence of null alleles in the population at low frequencies (Jarne and Lagoda 1996). The presence of null alleles at high frequency in the population can have implications for relatedness calculations, particularly for parentage analysis (Pemberton et al. 1995). We tested for the presence of null alleles at our loci by comparing the genotypes of several known motheroffspring pairs $(n=9)$ from SRS. We observed no evidence for null alleles at the 14 loci used in this analysis. We also repeated relatedness and Kinship calculations using only those loci at Hardy-Weinberg equilibrium $(n=11)$ and found that inclusion of the 3 loci did not alter results or conclusions; therefore, we retained all loci in the analyses. Relatedness calculations revealed a mean $r_{x y}$ of -0.01 for the 703 doe pairs (SE 0.006; range -0.43 to 0.56$)$, similar to the background mean $r_{x y}$ of -0.016 in the population of 368 deer from SRS.

\section{Correlations}

The bootstrap simulation on random kill locations suggested that use of random kill locations tended to underestimate correlation between

Table 1. Locus name, number of alleles, observed heterozygosity, expected heterozygosity, $P$-value for Hardy-Weinberg equilibrium (HWE), and polymorphic information content (PIC) for 14 microsatellite DNA loci genotyped for 368 white-tailed deer from the Savannah River Site, Aiken, South Carolina, USA, 2001-2002.

\begin{tabular}{lrrccc}
\hline & \multicolumn{4}{c}{ Heterozygosity } \\
\cline { 3 - 5 } Locus $^{\mathrm{a}}$ & Alleles & Observed & Expected & P.value & PIC \\
\hline BL25 & 6 & 0.623 & 0.671 & 0.205 & 0.624 \\
BM4208 & 20 & 0.861 & 0.903 & $<0.001^{\mathrm{b}}$ & 0.895 \\
BM6506 & 13 & 0.820 & 0.823 & 0.007 & 0.803 \\
BovPRL & 3 & 0.513 & 0.523 & 0.926 & 0.409 \\
Cervid1 & 14 & 0.836 & 0.831 & 0.304 & 0.810 \\
D & 10 & 0.824 & 0.838 & 0.561 & 0.819 \\
ETH152 & 12 & 0.750 & 0.822 & $<0.001^{\mathrm{b}}$ & 0.799 \\
INRA011 & 6 & 0.594 & 0.610 & 0.333 & 0.571 \\
K & 7 & 0.484 & 0.464 & 0.192 & 0.409 \\
N & 22 & 0.789 & 0.885 & $0.001^{\mathrm{b}}$ & 0.874 \\
O & 6 & 0.375 & 0.428 & 0.021 & 0.352 \\
OarFCB193 & 13 & 0.616 & 0.579 & 0.069 & 0.561 \\
P & 8 & 0.791 & 0.768 & 0.192 & 0.732 \\
Q & 16 & 0.867 & 0.881 & 0.497 & 0.870 \\
\hline
\end{tabular}

\footnotetext{
a Locus names from Anderson et al. (2002).

b Indicates locus not in Hardy-Weinberg equilibrium after Bonferroni correction
} 
DE- AI09-00SR22188

J. Wildl. Manage. 69(1):2005
Journal Article $\quad 2005$

05-41-P

WHITE-TAILED DEER GENETIC STRUCTURE • Comer et al.

339 spatial and genetic distances compared to mean telemetry locations, as $68 \%$ of simulated correlations were of lower magnitude than the correlation using telemetry locations. However, the $r$-value calculated from mean telemetry locations (-0.058) was close to the mean of simulations $(-0.048)$ and within the $95 \%$ confidence interval $(-0.08$ to $-0.01)$ for the simulations. Based on these results, we determined that the magnitude of the impact was relatively minor and that the inclusion of kill locations in the analysis was not likely to result in a true strong correlation being missed.

The Mantel test results revealed a weak correlation between linear distance and relatedness (correlation $=-0.08, P=0.058$ ) for the set of all does sampled. As further confirmation that this result was not due to the inclusion of kill locations in the spatial distance matrix, we conducted a second Mantel test using only the 17 radiocollared does (136 doe pairs) for which we had mean telemetry locations. With this subset, the correlation was even weaker $(-0.06, P=0.24)$. The results of spatial autocorrelation analyses were similar to the Mantel tests. We observed a weak correlation ( $r=0.036, P=0.003)$ at the smallest distance class and no autocorrelation at greater distance classes. The shape of the correlogram most closely resembled that typical for a general absence of spatial pattern as defined by Diniz-Filho and Campos-Telles (2002). Restricting the analysis to adult does eliminated 8 doe fawns from the Mantel test. The Mantel test correlation for adult does $(n=30)$ also indicated a weak correlation between linear distance and relatedness (correlation $=-0.071, P=0.14)$. The spatial autocorrelation analysis for adult deer only produced similar results with marginally significant autocorrelation at the smallest distance class $(r=0.038, P=0.021)$.

Correlation analysis for the subset of doe pairs with overlapping home ranges showed a stronger correlation between home-range overlap and relatedness for these deer $\left(r_{s}=0.55, P=0.02\right)$. To test whether the use of home-range overlap versus linear distance accounted for the difference in results, we also calculated Spearman's correlation for the same subset of deer pairs using the linear distance measure. The results were not substantially different except for the sign $\left(r_{s}=-0.51, P=\right.$ $0.04)$, which was expected (see methods).

\section{Relationship Categories}

Assigning the 703 doe pairs to relationship categories resulted in 10 pairs with first-degree relatedness, 29 with second-degree relatedness, and 664
Table 2. Number of pairs (n), type I and type II error rates, mean distance between point locations $(\mathrm{m})$, and mean relatedness scores $\left(r_{x y}\right)$ for white-tailed deer does in 3 relatedness categories at the Savannah River Site, Aiken, South Carolina, USA, 2001-2002.

\begin{tabular}{|c|c|c|c|c|c|}
\hline \multirow[b]{2}{*}{ Relationshipa } & \multirow[b]{2}{*}{$n$} & \multicolumn{2}{|c|}{ Error rate } & \multirow[b]{2}{*}{ Distance } & \multirow[b]{2}{*}{$r_{x y}$} \\
\hline & & Type I & Type II & & \\
\hline First degree & 10 & 0.01 & 0.036 & 3,303 & 0.397 \\
\hline Second degree & 29 & 0.05 & 0.304 & 3,872 & 0.196 \\
\hline Third+ degree & 664 & & & 4,746 & -0.026 \\
\hline
\end{tabular}

a Membership in relationship categories was determined from genetic data using the program Kinship 1.2.

unrelated (Table 2). Simulations in the Kinship program showed that distinguishing seconddegree-related pairs from unrelated pairs in our data was difficult, explaining the relatively high type II error rate for this category. The type II error rate in this analysis is the probability of falsely rejecting the null hypothesis and incorrectly assigning second-degree-related pairs to the unrelated category. However, we chose to minimize the chance that unrelated pairs were incorrectly assigned to higher relationship categories (indicated by $P=$ type I error rate). Box plots showed a slight upward trend in median distance between pairs from more closely related pairs to less related pairs (Fig. 2). However, we observed a high degree of overlap in distances among the 3 categories.

\section{DISCUSSION}

We found that the strength of association between genetic relatedness and spatial separation in female white-tailed deer varied depending

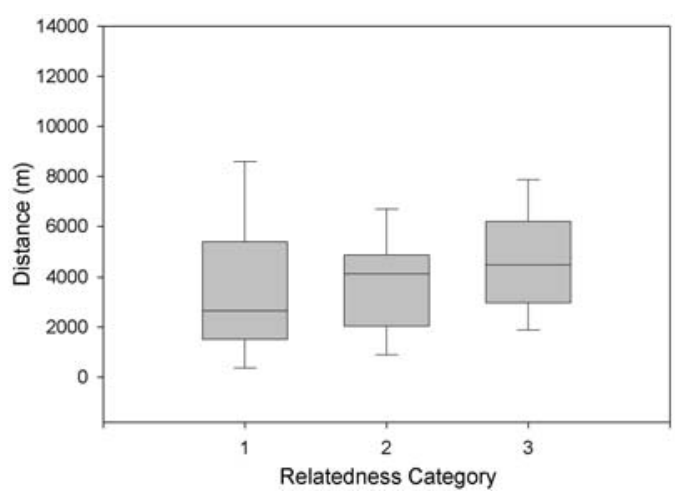

Fig. 2. Linear distances (meters) between white-tailed does for all doe pairs in 3 relatedness categories at the Savannah River Site, Aiken, South Carolina, USA, 2001-2002. Doe pairs were assigned to relatedness categories using the program Kinship 1.2 to analyze genetic data. Boxes show median distance and 25th and 75th percentiles. Whisker bars show 10th and 90th percentiles. 


\section{DE- AI09-00SR22188 Journal Article}

340

WHITE-TAILED DEER GENETIC STRUCTURE

- Comer et al. on the set of deer considered in the analysis. Among does with overlapping home ranges (spatially close), increased relatedness was associated with a greater degree of home-range overlap and smaller linear distance. In general, these results are consistent with the predictions of the rosepetal hypothesis. However, when all available doe pairs were included in the analysis the relationship was considerably weaker, suggesting that female deer were not forming social groups that follow a rose-petal pattern.

Of the 17 radiocollared doe pairs with overlapping home ranges, 9 had negative $r_{x y}$ scores indicating they were less related than a randomly drawn pair of individuals from the population. Five of these 9 pairs had only minor $(<10 \%)$ degrees of home-range overlap, but the remaining 4 pairs had between $13 \%$ and $27 \%$ homerange overlap. While these data did not support the rose petal hypothesis, some overlap of home ranges between unrelated deer at the boundaries of social groups is consistent with the model. Among the 136 doe-pairs in which both members were radiocollared, 8 pairs were classified as first or second-degree-related pairs. Of these 8 pairs, 5 $(63 \%)$ showed no overlap in their $95 \%$ kernel home ranges. The remaining 3 pairs showed a high degree of overlap (mean $=49 \%$, range $22-77 \%)$. One radiocollared doe pair was in the first-degree-relationship category; they shared $77 \%$ overlap in home range. These 2 deer were captured together when one was a fawn and the other was 4.5 years old. Genetic data confirmed this was a mother-daughter pair.

Using the spatial distance between doe pairs, we determined that many closely related doe pairs in the SRS herd were not associated spatially. In their study of social organization in the Adirondacks, Mathews and Porter (1993) delineated 8 social groups consisting of 3-9 does each. The maximum cumulative home-range size for a social group based on 95\% minimum convex polygons was $7.2 \mathrm{~km}^{2}$ (range 1.6-7.2 km²; Mathews and Porter 1993). Mean home-range sizes in the Mathews and Porter (1993) study were similar to or slightly larger than those observed at SRS (240 ha vs. $197 \mathrm{ha}$ ); therefore, this provides a conservative estimate of expected social group size. A social group range size of $7.2 \mathrm{~km}^{2}$ corresponds to a circle with a diameter of approximately 3,000 m. As a conservative estimate, the distance between any 2 points within the home ranges of deer in the same social group should be less than 3,000 $\mathrm{m}$. Among the 29 doe pairs with second-degree relat- edness, the linear distance between point locations was greater than 3,000 $\mathrm{m}$ for $18(62 \%)$ indicating that only $38 \%$ were probable members of the same social group. The mean distance between point locations was almost $4,000 \mathrm{~m}$, and the maximum distance was over $10,000 \mathrm{~m}$. In the 10 doe pairs with first-degree relatedness, 4 pairs $(40 \%)$ were more distant than $3,000 \mathrm{~m}$, including 1 pair that was over $8,800 \mathrm{~m}$ apart. These results indicate that at SRS only $38 \%$ of does that are second-degree related (grandmother-granddaughter, half-sibling, aunt-niece) and $60 \%$ of does that are first-degree related (mother-daughter or full sibling) remain socially affiliated and maintain overlapping home ranges. Eliminating doe pairs that include at least 1 fawn indicates that related adult deer are even less likely to be members of the same social group. Among adult does, $40 \%$ of first-degree-related doe pairs and $27 \%$ of second-degree-related doe pairs had a spatial separation consistent with membership in the same social group.

Overall, our results indicated a low degree of genetic structuring at the individual level among female deer at the SRS. These results are in contrast with previous studies showing a high degree of genetic structuring in female deer in this region (Purdue et al. 2000). However, Purdue et al. (2000) based their conclusions primarily on differences in mitochondrial DNA haplotypes. They found considerably less structure in biparentally inherited allozyme data. Furthermore, that study considered a much larger spatial scale than this study. Sample locations in Purdue et al. (2000) were $>25 \mathrm{~km}$ apart, and the entire SRS $\left(>800 \mathrm{~km}^{2}\right)$ is considered a single sample location. The maximum dispersal distance of $50 \mathrm{~km}$ described in Purdue et al. (2000) encompasses the entire 7,000-ha study area considered here. While their study provides an enlightening analysis of spatial and genetic structure in the southeast region, it does not address genetic structure at the level of the individual and the social group. Therefore, the results of Purdue et al. (2000) are fundamentally different in scale, and our results do not directly contradict theirs.

In their analysis of social and genetic structure among white-tailed deer in the Adirondacks, Mathews and Porter (1993) identified social groups based on spatial characteristics and then used allozyme data to determine whether these groups were genetically distinct. In an alternative approach, we used more precise microsatellite data to identify genetically similar individuals and 
DE- AI09-00SR22188

J. Wildl. Manage. 69(1):2005
Journal Article $\quad 2005$

05-41-P

WHITE-TAILED DEER GENETIC STRUCTURE • Comer et al. to examine the spatial relationships among these individuals. The patterns we observed in spatial and genetic distances were not consistent with the persistent, tightly bound social group structure described for the rose-petal hypothesis (Porter et al. 1991). A possible explanation for the weak correlation between spatial and genetic distances is that matrilineal social groups at SRS were not geographically independent as described by Mathews and Porter (1993). That is, social groups were present, but several such groups shared common spatial range. This also accounts for our observation that several pairs of does with significant home-range overlap were apparently unrelated. However, this scenario would be more likely if population density were elevated compared to the Adirondack range. Population density at SRS is low and generally comparable to that in the Adirondacks during the period of Mathews and Porter (1993). More importantly, this explanation does not account for our observation of numerous closely-related deer pairs that are spatially distant. Although we were unable to reject this hypothesis completely, it was not adequate to explain all of our observations.

The alternative explanation is that differences between our study area and the Adirondack study area prevented the formation of a rose-petal type social structure among SRS does. Important characteristics of the deer herd that could affect the social cohesiveness include such interrelated factors as migratory behavior, age structure, harvest history, and dispersal characteristics. The Adirondack deer herd is migratory, and deer make predictable seasonal movements between summer and winter ranges (Tierson et al. 1985). Seasonal group movements to and from winter range may strengthen social bonds and group cohesiveness (Nelson 1998). Like most southeastern deer herds, the SRS deer showed no consistent seasonal range changes.

The most striking difference between the Adirondack and SRS deer herds is the harvest history. The Adirondack herd has not been hunted since 1932, and female deer consistently reach older age classes ( $>10$ years; Aycrigg and Porter 1997). At the SRS, annual harvest is extensive: in 2002, hunters took 1,318 deer out of an estimated sitewide population of 5,500 (24\%). Does generally represent approximately $50 \%$ of harvested deer (52\% in 2002; 50\% in 2001). This high harvest rate among female deer has resulted in a young age structure among SRS does (Novak et al. 1999). In the 2002 harvest, $71 \%$ of does killed were $<3$ years old. Less than $4 \%$ of harvested does were in the $5.5+$ age class. Age structure among female deer may be an important factor in the establishment of social structure. Aycrigg and Porter (1997) found that matriarchal females were usually does $>5$ years of age and that deer in this age class showed the greatest degree of spatial structure. They found little spatial pattern in the home ranges of does $<5$ years of age.

A higher dispersal rate among female whitetailed deer at SRS could contribute to a pattern consistent with that observed in this study, where the subset of deer with overlapping home ranges showed more genetic and spatial structure. Dispersers are deer that make long distance movements and establish home ranges separate from their natal range (Nelson and Mech 1992). At larger spatial scales, including all deer pairs, the analysis included both disperser does and resident does (nondispersers). Dispersing deer were not related to other does close to their new home range, so their inclusion tended to weaken the association between spatial and genetic distances. However, limiting the analysis to those deer with overlapping home ranges reduced the proportion of pairs including a disperser and eliminated pairs of highly related individuals with high distances between them (i.e., a disperser and its mother or sibling). Therefore, the association between spatial and genetic distances would be expected to be stronger with this subset of deer.

Two lines of evidence suggest that dispersal rates among SRS does may be elevated relative to those observed in the Adirondacks where the rose-petal hypothesis was formed. First, we observed 2 putative dispersals (12\%) among the 17 radiocollared does in this study. However, dispersal in white-tailed deer typically occurs in the fawn or yearling age class (Hawkins and Klimstra 1970, Nelson and Mech 1992). Eight radiocollared deer were in the yearling or fawn age class when captured, including both deer that made putative dispersal movements. These data indicate a potentially higher $(25 \%)$ dispersal rate among young does at SRS. Our radiotelemetry study was not designed specifically to address dispersal, and the small number of doe fawns collared limits the direct evidence for elevated dispersal. However, the genetic analyses provide additional evidence for elevated dispersal rates. The only plausible explanation for closely-related deer pairs that are spatially very distant is that 1 or both members of the pair dispersed from their natal range in the past. With $>60 \%$ of second- 


\section{DE- AI09-00SR22188 Journal Article}

342

WHITE-TAILED DEER GENETIC STRUCTURE

- Comer et al. degree-related pairs and $40 \%$ of first-degree-related pairs separated by distances inconsistent with social group membership, our analyses suggest that dispersal has been a common occurrence.

High mortality among mature does has been associated with greater dispersal of female fawns. Nelson and Mech (1981) found that orphaned doe fawns in Minnesota showed erratic wandering movements that might indicate dispersal. Etter et al. (1995) found orphaned female fawns dispersed almost twice as often as non-orphaned fawns in Illinois. Annual mortality among does at SRS is approximately 25\%. Novak et al. (1991) found that SRS hunters tended to target older age classes preferentially, so mortality among mature does may be even higher. The resulting high orphaning rate could contribute to elevated dispersal rates among female deer. While our data do not provide definitive evidence for high dispersal rates among SRS does, elevated rates of dispersal provide a logical explanation for our observations.

\section{MANAGEMENT IMPLICATIONS}

Our results examine the applicability of the rose-petal model that underlies the localized management concept. The implications for localized management are currently unclear. The literature includes examples where localized management is recommended based on data showing high annual range fidelity (Kilpatrick and Spohr 2000, Grund et al. 2002, Porter et al. 2004). Our data indicate that such widespread recommendations should be made with caution. Female deer at SRS >2 years old exhibited high range fidelity, but little genetic structure was present in the herd. Using a population modeling approach to examine deer in a suburban environment, Porter et al. (2004) found that the ability to achieve a stable population size through culling or contraception was sensitive to the rate at which does dispersed into the removal area. Culling rates in excess of $75 \%$ were necessary to achieve a stable population when dispersal was 25\% (Porter et al. 2004). Elevated dispersal rates among young does could render the localized management concept less useful if vacant habitats are quickly recolonized by dispersing females. With increasingly liberal antlerless harvests in most states, female age structure in many herds may be more similar to that observed at SRS than to the older age structure present in the Adirondack deer herd. This underscores the need to develop a more complete understanding of social, genetic, and spatial structure in a deer herd prior to implementing management programs that rely on white-tailed deer social behavior.

\section{ACKNOWLEDGMENTS}

Our research was funded by the U.S. Department of Energy Savannah River Operations Office and through the U.S. Forest Service Savannah River under Interagency Agreement DEAI09-00SR22188. This research also benefited from support of the Environmental Remediation Sciences Division of the Office of Biological and Environmental Research and the U.S. Department of Energy through the Financial Assistant Award no. DE-FC09-96SR18546 to the University of Georgia Research Foundation. The University of Georgia Daniel B. Warnell School of Forest Resources and the U.S. Forest Service Southern Research Station also provided funding. The U.S. Forest Service Savannah River provided assistance with deer capture, and the Westinghouse Savannah River Company is gratefully acknowledged for access to samples and data. P. Johns provided field and laboratory assistance and helped in sample acquisition. We thank C. Drennan, M. Jennings, N. Mechlin, K. Settlage, B. Wirchansky, and J. Zastrow for field assistance, D. Osborn for logistical assistance, and M. Schable and L. Dueck for laboratory assistance. T. Campbell provided helpful comments on the analysis and draft manuscript, and the manuscript benefited from reviews by R. Warren, S. Castleberry, and 3 anonymous reviewers.

\section{LITERATURE CITED}

Anderson, J. D., R. L. Honeycutt, R. A. Gonzales, K. L. Gee, L. C. Skow, R. L. Gallagher, D. A. Honeycutt, AND R. W. DeYoung. 2002. Development of microsatellite DNA markers for the automated genetic characterization of white-tailed deer populations. Journal of Wildlife Management 66:67-74.

Aycrigg, J. L., AND W. F. Porter. 1997. Sociospatial dynamics of white-tailed deer in the central Adirondack Mountains, New York. Journal of Mammalogy 78:468-482.

Balloux, F., AND N. Lugon-Moulin. 2002. The estimation of population differentiation with microsatellite markers. Molecular Ecology 11:155-165.

Blouin, M. S. 2003. DNA-based methods for pedigree reconstruction and kinship analysis in natural populations. Trends in Ecology and Evolution 18:503-511.

BOHONAK, A. J. 1999. Dispersal, gene flow, and population structure. Quarterly Review of Biology 74:21-45.

Cole, L. C. 1949. The measurement of interspecific association. Ecology 30:411-424.

Conover, M. R. 1997. Monetary and intangible valuation of deer in the United States. Wildlife Society Bulletin 25:298-305. 
DE- AI09-00SR22188

J. Wildl. Manage. 69(1):2005
Journal Article 2005

05-41-P

WHITE-TAILED DEER GENETIC STRUCTURE • Comer et al. 343
D'Angelo, G. J., J. C. Kilgo, C. E. Comer, C. D. Drennan, D. A. Osborn, AND K. V. Miller. 2003. Effects of controlled dog hunting on movements of female white-tailed deer. Proceedings of the Annual Conference of the Southeast Association of Fish and Wildlife Agencies 57:317-325.

Dapson, R. W., P. R. Ramsey, M. H. Smith, and D. F. URBSTON. 1979. Demographic differences in contiguous populations of white-tailed deer. Journal of Wildlife Management 43:889-898.

DeYoung, R. W., S. Demarais, R. L. Honeycutt, R. A. Gonzales, K. L. Gee, And J. D. Anderson. 2003. Evaluation of a DNA microsatellite panel useful for genetic exclusion studies in white-tailed deer. Wildlife Society Bulletin 31:220-232.

Diniz-Filho, J. A., AND M. P. Campos-Telles. 2002. Spatial autocorrelation analysis and the identification of operational units for conservation in continuous populations. Conservation Biology 16:924-935.

Dusek, G. L., R. J. Mackie, J. D. Herriges, and B. B. Compton. 1989. Population ecology of white-tailed deer along the lower Yellowstone River. Wildlife Monographs 104.

Etter, D. R., C. M. Nixon, J. B. Sullivan, And J. A. Thomas. 1995. Emigration and survival of orphaned female deer in Illinois. Canadian Journal of Zoology 73:440-445.

Grund, M. D., J. B. McAninch, And E. P. Wiggers. 2002. Seasonal movements and habitat use of female whitetailed deer associated with an urban park. Journal of Wildlife Management 66:123-130.

Hardy, O. J., AND X. VeKemans. 2002. SPAGeDi: a versatile computer program to analyse spatial genetic structure at the individual or population levels. Molecular Ecology Notes 2:618-620.

Hawkins, R. E., AND W. D. KLimSTRA. 1970. A preliminary study of the social organization of white-tailed deer. Journal of Wildlife Management 34:407-419.

IMM, D. W., AND K. W. MCLEOD. In press. Plant communities. In J. C. Kilgo and J. I. Blake, editors. Ecology and management of a forested landscape: fifty years of natural resource stewardship on the Savannah River Site. Island Press, Washington, D.C., USA.

JARne, P., AND P. J. LAGODA. 1996. Microsatellites, from molecules to populations and back. Trends in Ecology and Evolution 11:424-429.

Kammermeyer, K. E., AND R. L. MarChinton. 1976. Notes on dispersal of male white-tailed deer. Journal of Mammalogy 57:776-778.

KILPATRICK, H. J., AND S. M. SPOHR. 2000. Spatial and temporal use of a suburban landscape by female whitetailed deer. Wildlife Society Bulletin 28:1023-1029.

LeberG, P. L., AND D. L. Ellsworth. 1999. Further evaluation of the genetic consequences of translocations on southeastern white-tailed deer populations. Journal of Wildlife Management 63:327-334.

Marchinton, R. L., AND T. D. AtKeson. 1985. Plasticity of socio-spatial behaviour of white-tailed deer and the concept of facultative territoriality. Pages 375-377 in P. F. Fennessy and K. R. Drew, editors. Biology of deer production. Bulletin 22. The Royal Society of New Zealand, Wellington, New Zealand.

Marshall, T. C., J. Slate, L. E. Kruuk, and J. M. PemBERTON. 1998. Statistical confidence for likelihoodbased paternity inference in natural populations. Molecular Ecology 7:639-655.
Mathews, N. E., AND W. F. PORTER. 1993. Effect of social structure on genetic structure of free-ranging whitetailed deer in the Adirondack Mountains. Journal of Mammalogy 74:33-43.

McNulty, S. A., W. F. Porter, N. E. Mathews, And J. A. HILL. 1997. Localized management for reducing white-tailed deer populations. Wildlife Society Bulletin 25:265-271.

McShea, W. J., H. B. Underwood, and J. H. Rappole. 1997. Deer management and the concept of overabundance. Pages 1-7 in W. J. McShea, H. B. Underwood, and J. H. Rappole, editors. The science of overabundance: deer ecology and management. Smithsonian Institution Press, Washington, D.C., USA.

MECH, L. D. 1983. Handbook of animal radio-tracking. University of Minnesota Press, Minneapolis, USA.

Nelson, M. E. 1998. Development of migratory behavior in northern white-tailed deer. Canadian Journal of Zoology 76:426-432.

—, AND L. D. MECH. 1981. Deer social organization and wolf predation in northeastern Minnesota. Wildlife Monographs 77.

— AND —. 1992. Dispersal in female whitetailed deer. Journal of Mammalogy 73:891-894.

NAMs, V. O. 1990. LOCATE II program. Pacer Publishing, Truro, Nova Scotia, Canada.

, AND S. Boutin. 1991. What is wrong with error polygons? Journal of Wildlife Management 55:172-176.

Nixon, C. M, L. P. Hansen, P. A. Brewer, And J. E. Chelsvig. 1991. Ecology of white-tailed deer in an intensively farmed region of Illinois. Wildlife Monographs 118.

NovaK, J. M., P. E. Johns, AND M. H. SMiTH. 1999. Current status of the SRS deer herd: demographic health and the attainment of management objectives. Ten year summary report. Savannah River Ecology Laboratory, Aiken, South Carolina, USA.

, K. T. SCRibner, W. D. Dupont, AND M. H. SMith. 1991. Catch-effort estimation of white-tailed deer population size. Journal of Wildlife Management 55:31-38.

OHNISHI, N., T. SAITOH, AND Y. Ishibashi. 2000. Spatial genetic relationships in a population of the Japanese wood mouse Apodemus argenteus. Ecological Research 15:285-292.

Otis, D. L., AND G. C. White. 1999. Autocorrelation of location estimates and the analysis of radiotracking data. Journal of Wildlife Management 63:1039-1044.

Oyer, A. M., AND W. F. PORTER. 2004. Localized management of white-tailed deer in the central Adirondack Mountains, New York. Journal of Wildlife Management 68:257-265.

Peakall, R., M. Ruibal, and D. B. Lindenmayer. 2003. Spatial autocorrelation analysis offers new insights into gene flow in the Australian bush rat, Rattus fuscipes. Evolution 57:1182-1195.

Pemberton, J. M., J. Slate, D. R. Bancroft, and J. A. BARRETT. 1995. Nonamplifying alleles at microsatellite loci: a caution for parentage and population studies. Molecular Ecology 4:249-252.

Porter, W. F., N. E. Mathews, H. B. Underwood, R. W. SAGE, AND D. F. BEHREND. 1991. Social organization in deer: implications for localized management. Environmental Management 15:809-814.

- H. B. UNDERWOOD, AND J. L. WOODARD. 2004. Movement behavior, dispersal, and the potential for 


\section{DE- AI09-00SR22188 Journal Article}

localized management of deer in a suburban environment. Journal of Wildlife Management 68:247-256.

Purdue, J. R., M. H. Smith, and J. C. Patton. 2000. Female philopatry and extreme spatial genetic heterogeneity in white-tailed deer. Journal of Mammalogy 81:179-185.

Queller, D. C., AND K. F. Goodnight. 1989. Estimating relatedness using genetic markers. Evolution 43:258-275.

Ramsey, P. R., J. C. Avise, M. H. Smith, and D. F. URBSTON. 1979. Biochemical variation and genetic heterogeneity in South Carolina deer populations. Journal of Wildlife Management 43:136-142.

Ratnayeke, S., G. A. Tuskan, and M. R. Pelton. 2002. Genetic relatedness and female spatial organization in a solitary carnivore, the raccoon, Procyon lotor. Molecular Ecology 11:1115-1124.

RAYMOND, M., AND F. Rousset. 1995. GENEPOP (Version 1.2): population genetics software for exact tests and ecumenicism. Journal of Heredity 86:248-249.

RICE, W. R. 1989. Analyzing tables of statistical tests. Evolution 43:223-225.

SAmbrook J., E. F. Fritsch, AND T. Maniatis. 1989. Mole- cular cloning: a laboratory manual. Second edition. Cold Spring Harbor Laboratory Press, Cold Spring Harbor, New York, USA.

SCRIBNER, K. T., M. H. SMith, AND R. K. Chesser. 1997. Spatial and temporal variability of microgeographic genetic structure in white-tailed deer. Journal of Mammalogy 78:744-755.

Severinghaus, C. W. 1949. Tooth development and wear as criteria of age in white-tailed deer. Journal of Wildlife Management 13:195-216.

Smouse, P. E., AND R. PeAKall. 1999. Spatial autocorrelation analysis of individual multiallele and multilocus genetic structure. Heredity 82:561-573.

-, J. C. LONG, AND R. R. SOKAL. 1986. Multiple regression and correlation extensions of the Mantel test of matrix correspondence. Systematic Zoology 35:627-632.

Tierson, W. C., G. F. Mattfield, R. W. Sage, and D. F. BEhrend. 1985. Seasonal movements and home ranges of white-tailed deer in the Adirondacks. Journal of Wildlife Management 49:760-769.

Associate Editor: DeWoody. 